\title{
On the Shaman Culture Embodied in the Novels of the Writers in Northeast China*
}

\author{
Yanhong Li \\ College of Foreign Languages and Literature \\ Jilin Normal University \\ Siping, China 136000
}

\begin{abstract}
The Shaman belief is prevalent in the ancient northern nations of China. The creation of writers in the Northeast China generally embodies the distinctive characteristics of the times, and shows the rich local color influenced by the Shaman culture. Under the contradictory psychological effect of national identity and conscious criticism of Shaman culture, the novels of the writers in Northeast China have more dialectical meaning in thought. Shaman culture, as a kind of cultural psychology, has infiltrated into the subconscious of these writers. It is also can be seen that Shaman culture is a living participant factor of history.
\end{abstract}

\section{Keywords-Shaman Culture; literature; Northeast China}

\section{INTRODUCTION}

The Shaman belief is prevalent in the ancient northern nations of China. Its origins are very early, which had been very developed and mature in the matriarchal society. As early as 3,000 years ago, the Manchu people's ancestor, Sushen people began to believe in Shamanism, who were forming a more systematic and national characteristics of the Shaman culture system. Until the near present generation, some northern minorities in China, even the Han people still believe in Shaman religion. The word "Shaman" originally contained the meaning of "wise, insight, inquiry" and so on, and gradually evolved into the fact that the shaman is the title, the special name of the Shamanist sorcerers who do "the god dance". Shaman has always been regarded as the mediator of the man-in-god communication, which is the biggest difference from other religious clergy. Shaman complete the process of "divine Possession" or "soul out of the shell" through dance, drumming, singing in order to communicate with the spirit, so as to achieve some hope.

The Shaman culture itself has the characteristics of primitive witchcraft, which shows the divine consciousness in the human spiritual world. Some of the Shaman ritual activities are direct witcheraft activities, but it does not perform one function. It is a multi-functional mix-and-thaw structure, which is a form of several social needs to be realized simultaneously. In addition to satisfying the need to use illusions to compensate for the shortcomings of primitive people in practice (which is realized by believing that rituals

*This paper is research results of Jilin Province Social Science Fund project, "A Comparative Study on Indian Shaman Culture and Manchu Shaman Culture". Project number: [2017JD33]. have supernatural powers of witchcraft), rituals also satisfy their needs for knowledge, education, lyrical and aesthetic. There are many kinds of plastic arts, such as masks and costumes, which show that the Shaman culture has its own blending nature, which not only satisfies the people's spiritual demand, but also satisfies the people's aesthetic demand.

Either way, Shaman's manifestations cannot be separated from the original dance, drum ring, chanting mnemonics and other seemingly extremely ancient mysterious ritual dance, this dance is collectively known as "Shaman Dance". The ancient mystical dance of Shaman dance is the most important manifestation of Shamanism. In general, the Shaman Dance has two main features. One is the feature of ritual. Ceremonies are "a special responsibility" or "obligation". This special responsibility for shaman Dance is to complete the Shaman's obligations for the community or people in order to achieve true redemption. Shaman Dance is not a simple dance, not pure entertainment, not even the kind of mysterious communication between man and God as people imagined. It is closely related to Shaman culture, and it is related to the belief of that "all things have spirit" in Shamanism, thus more embodies the faith of man's piety and sincerity. The other is the symbolic character. Symbolic symbols in ritual contexts refer to objects, actions, relationships, events, postures and spatial units in the context of rituals, which traditionally represent other things beyond themselves, and which have far-reaching meanings, which is what we call a symbol. The instruments of the Shaman include Shaman's costume, Shaman's cap, Shaman's drum, waist bell, bronze mirror, belt and so on. The purpose of these instruments is not to perform, but to connect God, is a symbol of all kinds of divine power and spirit, embodies the spiritual connotation of Shamanism, and thus has the same effect as the picture or statue of a god, and cannot be desecrated. It is undeniable that people have generally accepted the folk culture form of Shaman dance and consciously and unconsciously injected this folk culture factor into the cultural creation.

In terms of the various forms of cultural creation we know, literature and local operas involve the Shaman Cultural Elements, which are the most deeply influenced cultural form. The Shaman culture has exerted far-reaching influence on the writer's literary creation the performance of 
local operas in northeast China, which is manifested in content, attitude and even style.

\section{SHAMAN CULTURE IN LiterATURE OF NORTHEAST CHINA}

The creation of writers in the Northeast China generally embodies the distinctive characteristics of the times, while the rich folk-cultural description in the novel fades the political utilitarian color, increases the cultural content and aesthetic value, has a rough and grand style, writes out the customs and sentiments in the northeast, and shows the rich local color influenced by the Shaman culture. In their works, they express their own folk experience, the pain of home country and the real political requirements, so, the aesthetic and significance in their works get a natural fit, which also constitutes the special significance that the Northeast writers adds color to Chinese modern literature in the Chinese modern history. In this paper, the literary creation of Xiao Hong, Chi Zijian, Duanmu Hongliang, and Liu Qing will be analyzed from the cultural implication, aesthetic characteristics and so on to understand the unique connotation of the Shaman Cultural description in Northeast writers.

\section{A. Recognition of the Shaman Culture}

With the development of history, Shamanism penetrates into the living customs and cultural psychology with the deep influence of invisibility. The Northeast writers have the latent temperament endowed by Shamanism culture, and they are consciously or unconsciously present in their literary creations. Shamanism has become a kind of cultural spirit with rich content, and it has become a unique regional culture spirit in the northeast folk culture. This cultural spirit has long influenced and infiltrated the Northeast writers, and formed a deep cultural accumulation in their hearts.

The cultural factor is the important link that binds a nation closely together, and people who belong to the same nation have a kind of identity mentality to the culture of their own nation. Shamanism culture is a part of Manchu culture, Duanmu Hongliang's mother is Manchu people, and he volunteered to his emotional position in favor of the matriarchal, and got the national identity of self-satisfaction. Therefore, in the face of their own national Shamanism cultures, out of the national identity, Duanmu Hongliang first has held a positive attitude to the Shamanism culture which has a realistic function and entertainment function.

Duanmu Hongliang's Ke' er' qin Prairie, Great River, The Sea of the Earth and other novels have a lot about God activity description of the Shamanism culture, the magnificent activities of worship heaven, and people's piety which were described by Duanmu Hongliang incisively and vividly. In the works of Duanmu Hongliang, people reached the realm of the unity of human and God, and the convergence of man and the universe through the pious prayer. Under the influence of the latent identity psychology of Shamanism, the writing of Shamanism culture in Duanmu's works has a unique appeal and appeal in the objective. In the rural areas of the countryside, the local religions are very strong in gameplay and enchantment.
These charms fell in their depressed corner of the spirit and the body's formal faculties, so that they got some kind of intricate satisfaction, and the patient's chronic disease did well and got cured. As a witness to the activities of Shamanism, Duanmu Hongliang admits that Shamanism culture does have the function of saving lives, and also affirms that Shamanism culture, as a recreational activity, brings fresh visual and auditory experiences and feelings to the villagers' backward living conditions in the writing of Shamanism culture. Shamanism occupies a very important place in the lives of these people, and it incorporates the subconscious mind to a certain degree of liberation of their spiritual world, freeing them from fear and uneasiness, and the healing of physical or mental illnesses.

Duanmu Hongliang not only presents the national identity of Shamanism culture by describing a great deal god activities of Shamanism in the novels, but also makes Shamanism rise to a kind of permeable cultural and artistic spirit in his novels. Duanmu Hongliang's Great River and The Sea of the Earth have this kind of writing features. At the beginning of Great River, the author describes the grandeur of the great river, although the statement is short, but emotional agitation, momentum heroic as if the Shaman is dancing god in the activities of the Shaman possessed, which shows that Duanmu have the power of such writing. In The Sea of the Earth, a group of parallel sentences at the beginning of the second paragraph drive the emotional tone of the novel from the momentum and rhythm obviously as if the Shaman is in a state of emotional catharsis in the process of dancing god. There are many similar expressions in his novels. He said that the feelings here are not decorated, such as a person in the sad, then, in his chest, must be able to hear the heart cracked, such as crying. The dripping drops of water will also reveal a vibrating metal sound, and the inevitable whole soul will arouse a gloomy echo. Whether it is in The Sea of the Earth or Great River, Duanmu Hongliang uses his pen to present the unique regional culture in the Northeast China with its strong and hard-to-suppress emotion.

Chi Zijian's The Right Bank of Eerguna River can be said to be a centennial epic of the Ewenki nationality, living in Heilongjiang Province, China. The novel shows all the details of Shamanism culture, and tells the historical facts of the two Shaman's legendary lives and the indomitable struggle of the whole nation from the destiny. Chi Zijian's attitude towards the shaman is a kind of appreciation and recognition, full of the attachment and remembrance of the culture of the Ewenki. In Chi Zijian's works, the Ewenki people believe in the Shaman and believe that Shaman has superhuman powers of mystery, they can save people's lives, and they can devote themselves to the nation and the tribe. The author, with a solemn tone, has no doubt about the divine radiance that has been revealed to them, and the perspective of the description is the experience of being in it, the equal treatment and the wordless care. Although the Shaman possesses the supernatural power that ordinary people do not possess, it also pays a heavy price for his divine power. To attain divine power, it must be paid, even sacrificed. Nihao inherited the mantle of Nidu Shaman, but 
when Nihao save every person, she will lose one of her children. As a Shaman, her duty is to save lives, even if the guilty guy "Mafenbao" and the young stealing the reindeer needed, she will rescue them with wearing the divine clothes to dance god. Finally, Nihao died in order to pray for rain, and she repaid god's gift with her own sacrifice. Shamans use life to gain divine power, to complete the handover with God at the cost of life. God does not bestow it for nothing, but merely completes a transformation that tends to keep a balance and harmony. Through the works, we can see Chi Zijian's attitude towards life and death that born in nature, died in nature, life is just a cycle. This is the life view of the unity of man and nature, and the universe view of the harmonious coexistence of heaven and earth and man.

\section{B. A Critique of Shaman Culture}

In the $1930 \mathrm{~s}$, a lot of outstanding young writers were influenced by May 4th New Culture Movement and Lu Xun's cultural criticism. Under the influence of May Fourth new cultural thoughts, those Northeast writers who awakened together became the heirs of the spirit of "reforming national standard of the people", calling for science and democracy, opposing autocracy and superstition, making the sound of enlightenment to the ignorant people, and pointing the cultural criticism to the anesthetic man and Shamanism to fool people. In the 1930s, accepting Lu Xun's cultural criticism, Xiao Hong, Duanmu Hongliang and other people held a clear rejection and confrontation of the psychology on the Shamanism in the literary creative motive, and they often highlighted the negative effects of Shamanism in their works, regarded the god dance of Shaman as ignorant and backward feudalistic superstition together to criticize. At that time, the trend of science and democracy of the new culture movement has foreshadowed the fate of Shamanism's culture which began to withdrawal from the historical stage.

Although the god dance of Shaman gave people the experience and enjoyment of the beauty in the visual and auditory feelings, it corroded and paralyzed the spirit of the nation; in the face of backward cultural factors or the bully of the ruling class, they could only choose to accept blindly. Based on the appeal of reforming national standard of the people, Duanmu Hongliang consciously denounced and criticized the aspects of Shamanism's Corrosion and persecution of the nationals. In the work of Duanmu Hongliang, the god dance of Shaman is hypocritical and deceptive, which cannot save the people at the bottom of the national crisis, but aggravate their spirit of numbness and backwardness. In his novel Great River, facing to the villagers who held the spirit of numbness but did not recognize by themselves, he finally let Tieling break out of the cage of feudal etiquette to beat "the great God" as a revolt against the backward religious culture. In Ke' er' qin Prairie, Duanmu Hongliang dealt a powerful blow to this despicable act that Shamanism culture is not only the spiritual opium to poison the people, but also the tool that the landlord class covered the eyes of people after they annexed these lands.
In the works of Xiao Hong "the Big God dance" is not the true meaning of the Shaman dance. But because the two forms and their contents are similar, Xiao Hong criticized "the Big God dance" as a feudal superstition, revealing its deceptive nature. In the novel, Tales of Hulan River, there are many classic descriptions of "the Big God dance". In the first section of the second chapter, Xiao Hong linked the "the Big God dance" and the fate of Xiaotuanyuan's wife closely to expose that "the Big God dance" is ignorance and cruelty. The exaggerated description of the "Great God" makes the reader feel that the "great God" is purely a juggling doll in the author's eyes, whose action completely loses the symbolic character of the Shaman Dance. The same is true of "temple fairs" and "river lanterns". People along Hulan River are enchanted with "the Big God dance", not out of the power of faith, but due to blind superstition or observation. The implication of the works is that the folk culture such as "the Big God dance" reflects the poverty of the material world and the emptiness of the spiritual world, which is the soil in which the activity of "the Big God dance" exists. The activities of "the Big God dance" attached to the fate of Xiaotuanyuan's wife were very cruel and terrible, which made her life come to an end worthlessly. People not only watched the tragedy happen, but also lived as usual the next day, as if they were not affected by the slightest thing. People's ignorance and numbness have reached the highest point. People are not in charge of their own fate, but handed over to the illusionary ghost. With deep sympathy and resentment, the author exposes that the folk custom of "the Big God dance" is harmful to the villagers. In the work of Xiao Hong, "the Great God" is the secular ones who jumped from the altar. They sought their own interests, and there was nothing sacred about them. What is more abhorrent to people is that they are like the bad wolf in sheep's clothing, devouring the living life one by one by mouth. The dances they danced had nothing to do with Shaman belief, but a means of fooling the common people. This ancient folk culture in the cultural dimension and value orientation has not been recognized by Xiao Hong, on the contrary, got the cold scrutiny and criticism presented by the author. The seemingly ethereal and calm brushwork reveals the heavy and depressing reality: primitive, ignorant and backward.

\section{To Reproduce the History of Homeland by Shaman Culture}

In the description of many thinkers or modern thoughts, Shaman must be a backward thing, which needs to be enlightened and deconstructed. However, in the novels of some writers in Northeast China, we can see that Shaman culture is a living participant factor of history, showing its own charm.

Close reading the novel Lip Code written by Liu Qing, which is from Northeast China, it is not difficult to find that some of the main characters are active images, such as Lang Wuchun, Mandou, Liuzhi, Shaman Li Liang, and so on, their Manchu identity is beyond doubt. In the text, a great deal of space is also devoted to the full description of Shaman culture with the characteristics of Manchu culture. 
In the novel Lip Code Liu Qing wrote, "The Shaman is the first wise man in the world who keeps track of the divine world, the beast world, the spiritual world and the soul world." "I" in the novel, named Mandou, is a specific person. "He is a cat-eyed boy who will see more, others' day is his day, others' night is daytime to him." He can see things that no one else can see and get into other people's dreams. Writing such a Shaman culture, such a psychic, will be turned into metaphysics if not careful, but the novel Lip Code let these magical writing be implemented in the specific history and life, Shaman is no longer the novel's cultural label, but become the spiritual texture of the novel. In these plots that Shaman Li Liang made exorcism for Liuzhi and cast spells for enthronement of the Emperor Puyi, the author Liu Qing not only shaped the image of Shaman Li Liang, but also successfully made us understand the important influence of Shaman culture on a group of people.

The land and nature of the novel Lip Code, which includes many of the trees written by the author, is another dimension, which is calm, vast and inclusive, which can quell all anger, and can dissolve all grudges. As the author writes, in the eyes of the Kuyala people, each tree has a soul, there are souls, which can understand the language of people, will also send a pleasant voice to soothe people. When these trees are abandoned, felled and destroyed, it means that human life is also decaying and withered. Human life is connected with the life of a tree. The same is true of nature. Mountains, rivers, vegetation, livestock in the novel Lip code are spiritual, and full of mystery, in which the human life has countless souls of the companion, no longer lonely. The dialogue between man and nature is another portrayal of man and history. The Shaman culture throughout the novel provides assistance to every soul. Mandou said, "There is a voice in my ear that tells me that every action on earth corresponds to God. In the wilderness, the God of love moves your hair, the God of love senses that you have fallen in love, the God of mist wets your temples, the God of joy sings with the magpie, and the God of darkness comes sooner than tragedy, and in every misfortune there is a cool wind of pity and sorrow. The difficulties of life are also caused by the Gods, which can only be eliminated with the help of a good spirit, and this medium is the Shaman with infinite belief. The supreme goal of the Shaman is to speak in the name of the deceased and be possessed by an ancestor's soul, to give a good-natured answer to the deep trust and hope."

The novel Lip Code is full of divine writing, but this divinity is not purely imaginary, surreal, it is a daily. Shaman is a symbol of divinity, but more of a daily nature. As a ghostly existence, it is not only the liberation of the writer's imagination, but also a unique perspective of observing the world and observing people. Like Li Liang and Mandou, these Shamans in the novel, are witnesses as well as the rebels. This century about the modern and progressive myths is questioned because of their Shamans' existence, and the history presents different dimensions of understanding, and the novel also opens up another vast spiritual space.

The novel shows how the Shaman has played a role as a witness of history, as a historical participation in the course of the history of the 20th century from the world of literature. The novel Lip Code describes a "life and death field" in China over the past century, covering the historical events that have gone through many decisive times since the 1910 . If you have some knowledge of China's modern history, you will know that the continuous political movements, all kinds of wars and various changes arising, like a gust of wind, are very mysterious in themselves. The novel also describes all kinds of bandits, droughts, insect disasters and so on that happened in northeast China and how people survive and drift among them? The novel vividly reflects the severe disasters, miserable wars and tangled fates in Northeast China in the past 100 years which is a history of the struggle of life and death. Although the novel has no intentional epic pursuit, it is presented through the primitive state to achieve the epic character factor. The novel has a broad pattern and broad vision. It blends the fate of history and individual characters which shows a strong sense of destiny and thoughts. The novel Lip code is not so much a full-length novel about the miserable fate of the Manchus in the first half of the 20th century as a century-old national memory of Northeastern China.

\section{CONCLUSION}

Critical satire is not the root, and sympathy and sorrow are not the source. As the writers of the black land in Northeast China, all have concern for the people's livelihood with the feelings of compassion and hold a deep love for this land. Their works are like a kind of good medicine for people to find the true meaning of life. This kind of humanistic feeling, this kind of folk perspective and this kind of bending attitude reflect the unique feelings of the people in Northeast China.

The cultural factors such as secular public sentiment, historical tradition, folk belief and value concept in the regional culture have endowed the writer with a concern for people's livelihood and feelings of life. The author's display of unique cultural landscape and the description of folk customs with regional characteristics also make their novels full of human happiness and warm home atmosphere. What is most rare is that through the seemingly fairy-tale descriptions of the writers, we can feel that the disappearing Shaman and their nation are struggling with the intangible destiny. With sympathy and compassion, they gave deep love to the group of people represented by the shaman on the black land in order to settle their unyielding souls. Compassion comes from deep concern, from deep love, from broad-mindedness and from immortal amorous feelings of the black land. Shaman as a culture in the reality has slowly disappeared, but has been vividly reproduced in the writers' works of Northeast China. It is a historical reappearance, but also the appearance of the writer's mental journey. In our bemoaned sigh, the land is still spewing fragrant, and life is still bearing the burden.

Under the contradictory psychological effect of national identity and conscious criticism of Shaman culture, the novels of the writers in Northeast China have more dialectical meaning in thought. Shaman culture, as a kind of cultural psychology, has infiltrated into the subconscious of 
northeast writers. The study of Shaman culture writing in their novels can also reveal the rich inner world and cultural connotation of these writers.

The folk culture of each nation is valuable spiritual wealth, and the writing of Shaman culture in northeast novels plays a positive role in the inheritance of Manchu Shaman culture. Studying the writing of Shaman culture in their novels and grasping their positive and critical value trend of Shaman culture can help us to form a comprehensive understanding of Shaman culture and provide a powerful reference for us to study the folk customs of minorities in the Northeast China.

\section{REFERENCES}

[1] Chi Zijian. The Right Bank of Eerguna River. Beijing: Beijing Shiyue Literature and Art Press, 2005.

[2] Duanmu Hongliang. Selected Work of Duanmu Hongliang, Volume I. Beijing: Beijing Press, 1998.

[3] Duanmu Hongliang. Selected Work of Duanmu Hongliang, Volume II. Beijing: Beijing Press, 1999.

[4] Liu Qing. Lip Code. Beijing: The Writers Publishing House, 2017.

[5] Xiao Hong. Tales of Hulan River. Shanghai: Yilin Press, 2005. 